\title{
A Simple, Inexpensive Holographic Microscope
}

\section{Citation}

Dimiduk, Thomas G., Ekaterina A. Kosheleva, David Kaz, Ryan McGorty, Emily J. Gardel, and Vinothan N. Manoharan. 2010. A simple, inexpensive holographic microscope. In Digital Holography and Three-Dimensional Imaging, OSA Technical Digest (CD), paper JMA38. http:// www.opticsinfobase.org/abstract.cfm?URI=DH-2010-JMA38.

\section{Published Version}

http://www.opticsinfobase.org/abstract.cfm?URI=DH-2010-JMA38

\section{Permanent link}

http://nrs.harvard.edu/urn-3:HUL.InstRepos:8300209

\section{Terms of Use}

This article was downloaded from Harvard University's DASH repository, and is made available under the terms and conditions applicable to Open Access Policy Articles, as set forth at http:// nrs.harvard.edu/urn-3:HUL.InstRepos:dash.current.terms-of-use\#OAP

\section{Share Your Story}

The Harvard community has made this article openly available.

Please share how this access benefits you. Submit a story.

\section{Accessibility}




\title{
A Simple, Inexpensive Holographic Microscope
}

\author{
Thomas G. Dimiduk ${ }^{1}$, Ekaterina A. Kosheleva ${ }^{1}$, David Kaz ${ }^{1}$, Ryan McGorty ${ }^{2}$, \\ Emily J. Gardel ${ }^{2}$, Vinothan N. Manoharan ${ }^{1,2}$ \\ ${ }^{1}$ Department of Physics, Harvard University \\ ${ }^{2}$ School of Engineering and Applied Sciences, Harvard University \\ tdimiduk@physics.harvard.edu
}

\begin{abstract}
We have built a simple holographic microscope completely out of consumer components. We obtain at least $2.8 \mu \mathrm{m}$ resolution and depth of field greater than $200 \mu \mathrm{m}$ from an instrument costing less than $\$ 1000$.

OCIS codes: (090.0090) Holography, (180.0180) Microscopy.
\end{abstract}

\section{Introduction}

Holographic microscopes have the potential to avoid some of the complexities of conventional microscopes. A holographic microscope focuses numerically, reducing the need for mechanical translation. Holography is inherently three dimensional, a capability otherwise requiring confocal or other complicated apparatus. Holography intrinsically possesses phase contrast without a specialized illumination system. Finally, recent advances in semiconductor technology have now combined to make it possible to build a holographic microscope out of mass-market consumer components. Combined with the simplicity inherent in holography, this gives the possibility of a three dimensional imaging system which is simple and inexpensive, very inexpensive relative to other scientific microscopes. Such a microscope then becomes a module that can be cheaply and easily added to another apparatus instead of being a dominating focus of design. Cost reduction by an order of magnitude or more will also allow such microscopes to be used in places where microscopes were not even considered previously, particularly in industry, medicine, and education.

We present an example of such a simple microscope. The core of our apparatus is a consumer digital camera, a battery powered diode laser, a microcontroller and a generic microscope objective. Even with supporting optics and structure, the total component cost is well under $\$ 1000$. With this minimal instrument we are still able to achieve resolution in excess of $3 \mu \mathrm{m}$ and depth of field in excess of $200 \mu \mathrm{m}$.

\section{Apparatus and Methods}

We are primarily interested in transparent colloidal and biological samples, so we can make use of inline holography to keep complexity down. Our apparatus, Fig. 1, consists of, from top to bottom, a Canon EOS 300D digital camera, a Newport 20x 0.4 NA microscope objective, a slide holder mounted to a 3 axis micrometer stage, a beam telescope, a $785 \mathrm{~nm}$ laser diode, and an Arduino microcontroller board. The Canon EOS 300D is a 6.3 megapixel camera with a 3088x2056 pixel $22.7 \mathrm{~mm}$ x $15.1 \mathrm{~mm}$ CMOS sensor. The microscope objective sufficiently magnifies hologram fringes for adequate resolution by the camera's $7.35 \mu \mathrm{m}$ square pixels. Illumination from the $785 \mathrm{~nm}$ ADL 78901 laser diode is expanded by the beam telescope to increase uniformity across the field of view.

Control is centralized under the Amtel ATMega168 microcontroller based Arduino board from Adafruit Industries. It controls the camera's external shutter release with a digital output and a transistor that powers the laser diode with an analog output. We synchronize the camera shutter with a laser pulse, allowing imaging with a $2.3 \mathrm{~mW}, 80 \mu \mathrm{s}$ pulse (power measured with a Thor Labs PM 100). The camera stores images internally on a flash memory card. Combined with battery power for all components, this allows the instrument to capture holograms in a completely self contained manner.

After an experiment, we transfer images to a standard computer for reconstruction. We reconstruct using the convolution method described by Schnars and Juptner [1] and extract both phase and amplitude information. We take into account the action of the lens as described by Sheng [2]. We preform reconstructions using custom software written in Python with the SciPy numerical library and running on a $3 \mathrm{GHz}$ Intel Core 2 Duo CPU.

We determined the resolution of our instrument by imaging a USAF 1951 resolution test target manufactured by Edmund optics. We investigated imaging capabilities with $2 \mu m$ Invitrogen sulfate latex particles embedded in Knox Gelatine. We made an $\sim 200 \mu m$ thick sample using vacuum grease as a spacer between a slide and a number one 


\section{JMA38.pdf}

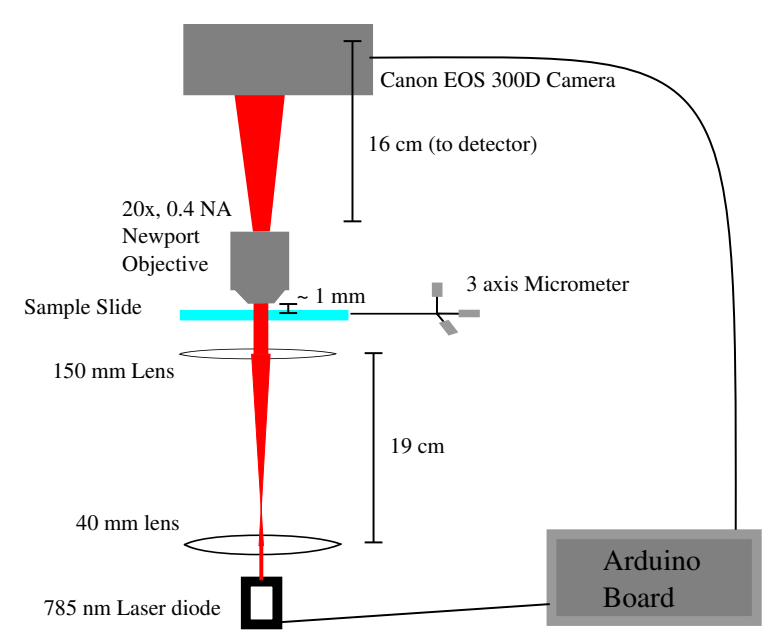

Fig. 1: Diagram of the microscope apparatus. Distances indicated can be varied by at least $10 \%$ without substantially affecting operation.

cover slip. We loaded gelatin hot, once cooled it solidified preventing sedimentation, keeping a sample interesting in three dimensions.

\section{Results}

We determined the resolution of our instrument to be at least $2.8 \mu \mathrm{m}$. Fig. 2 shows the hologram and reconstruction we used to establish this resolution. The second smallest resolution element is discernible and contains elements spaced by $2.8 \mu \mathrm{m}$. This resolution is approximately a factor of three worse than the $\sim 1 \mu \mathrm{m}$ diffraction limited resolution of our 0.4 NA objective at $785 \mathrm{~nm}$. We believe this resolution defect is from a combination of loss of fringes spaced too finely for the camera's pixels and from obscurement of fringes by sensor noise, illumination inhomogeneity, and reflection and scattering from optics.

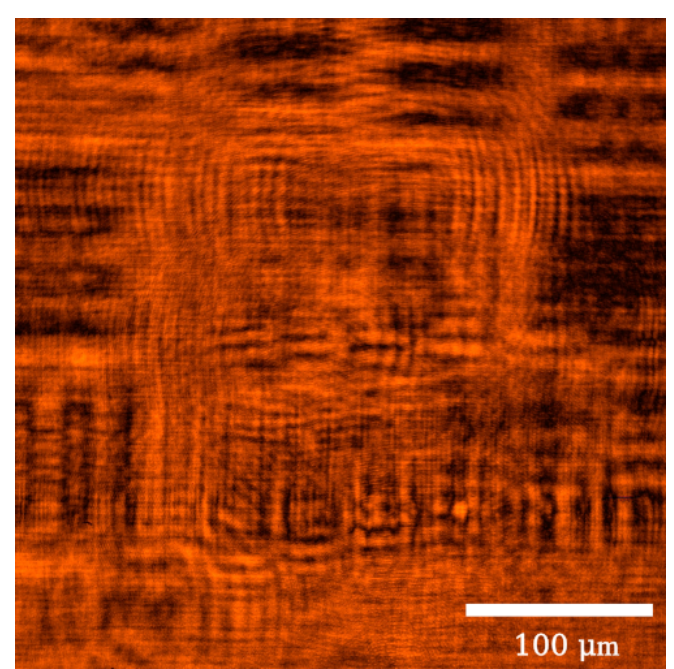

(a) Hologram

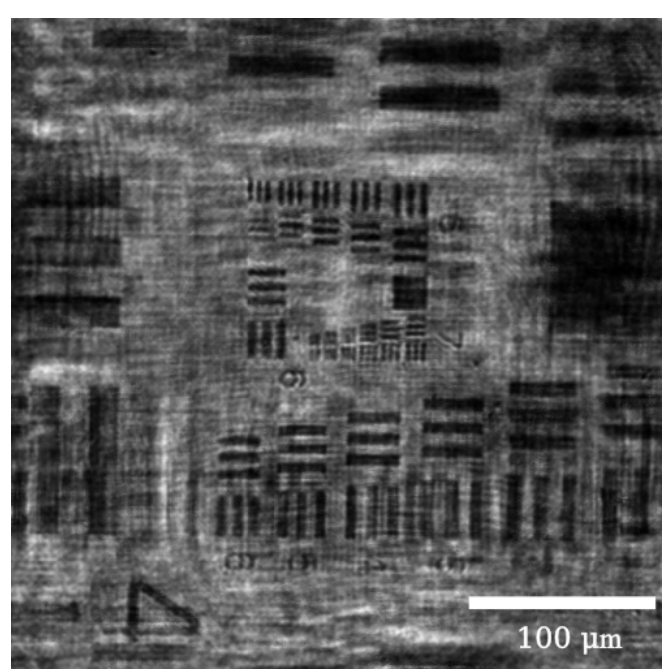

(b) Reconstruction

Fig. 2: Image of USAF 1951 resolution grid showing $2.8 \mu \mathrm{m}$ resolution

We demonstrate three dimensional imaging and broad depth of field with $2 \mu \mathrm{m}$ sulfate latex colloids embedded in gelatin. From a single hologram, Fig. 3(a), we can reconstruct at many different planes and visualize distinct particles, example planes are shown in Figs. 3(b-d). 


\section{JMA38.pdf}

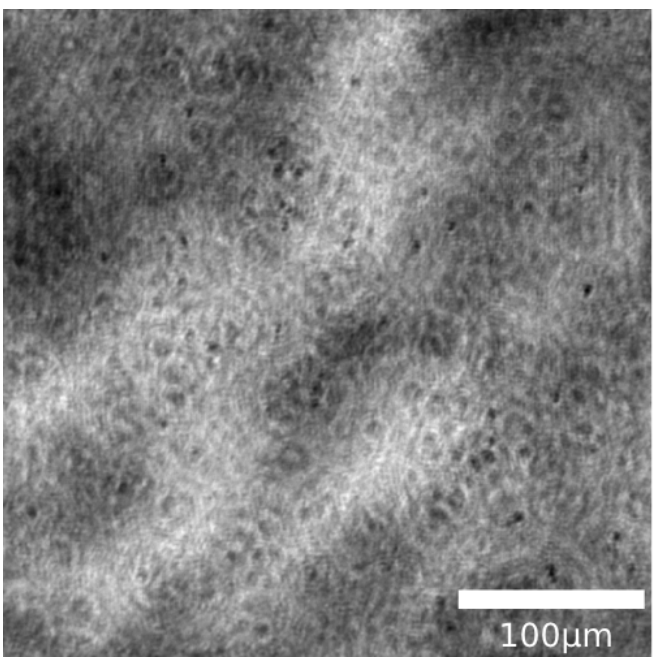

(a)

Holo-

gram

(b) Amplitude Reconstruction $z=220 \mu \mathrm{m}$

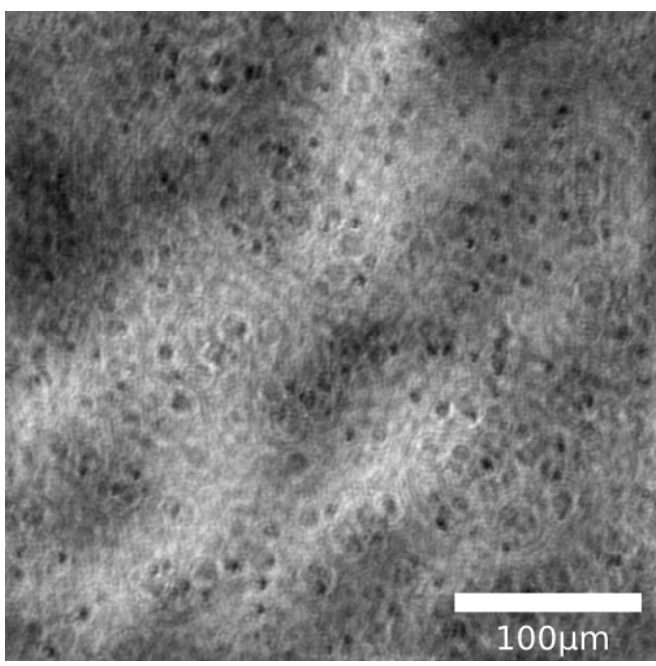

(c) Amplitude Reconstruction $z=320 \mu \mathrm{m}$

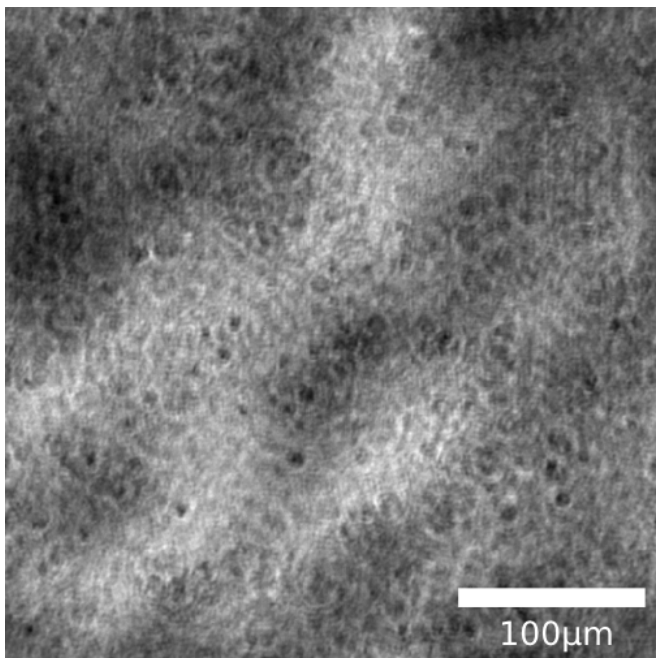

(d) Amplitude Reconstruction $z=420 \mu \mathrm{m}$

Fig. 3: Sulfate Latex Particles in gelatin

\section{Conclusion}

We demonstrate the feasibility of constructing a simple, low cost holographic microscope with nonetheless useful capabilities. We show that a straightforward implementation can achieve at least $2.8 \mu \mathrm{m}$ resolution and at least $200 \mu \mathrm{m}$ depth of field.

With more advanced background subtraction and noise reduction algorithms and further optimization of the optical path, a sub $\$ 1000$ microscope that approaches diffraction limited resolution should be possible. This design keeps difficult optics to a minimum, facilitating implementation by those not traditionally involved in holography.

[1] U. Schnars and W. P. Juptner, "Digital recording and numerical reconstruction of holograms" Measurement science and technology 13,85101 (2002).

[2] J. Sheng, E. Malkiel, and J. Katz, "Digital holographic microscope for measuring three-dimensional particle distributions and motions" Applied optics 45,38933901 (2006). 